\title{
GESTÃO DA QUALIDADE NA EDUCAÇÃO
}

\author{
Adriana Paula Cassol ${ }^{1}$ \\ Ismar Henriques Silveira² \\ Michael Eberle Siemeintcoski ${ }^{3}$ \\ Sérgio Roberto Arruda ${ }^{4}$ \\ Silvio Bitencourt da Silva ${ }^{5}$ \\ Simone Moraes Raszl $\left.\right|^{6}$
}

\section{RESUMO}

A qualidade na educação tem diferentes definições, que dependem do ponto de vista sob qual é analisado. A gestão da qualidade na educação busca a melhoria dos processos, independente da definição aplicável. O objetivo deste artigo é analisar os benefícios da implementação de um sistema de gestão da qualidade na educação com base no ciclo PDCA. $\mathrm{O}$ artigo foi escrito com base em um levantamento bibliográfico. A metodologia PDCA tem quatro etapas: planejar, executar, controlar e estabelecer ações que possam corrigir os rumos e encaminhar para um novo ciclo. Ao planejar, estabelecer objetivos e metas, construir métricas, acompanhar indicadores, analisar resultados e propor planos de ações preventivas ou corretivas, estão sendo identificadas as necessidades de interferência e oportunidades de melhoria na educação. O presente estudo identificou alguns casos onde a aplicação da metodologia PDCA em processos educacionais comprova os estudos teóricos que reforçam a importância da implementação de gestão da qualidade na educação.

Palavras-chave: Educação. Gestão. Qualidade.

\footnotetext{
${ }^{1}$ Especialista,e-mail: cassol@sc.senai.br

${ }^{2}$ Especialista,e-mail: ismar@sc.senai.br

3Mestre,e-mail:mes@sc.senai.br

${ }^{4}$ Mestre,e-mail:arruda@sc.senai.br

${ }^{5}$ Mestre,e-mail:silvio@sc.senai.br

${ }^{6}$ Mestre,e-mail: simone@sc.senai.br
} 


\section{INTRODUÇÃO}

Relatórios de avaliação de eficácia indicam que a qualidade da educação brasileira apresenta baixos índices de desempenho se comparados com os de outros países do mundo, especialmente se forem considerados os Relatórios do Programa Internacional de Avaliação de Alunos (PISA) (ORGANISATION FOR ECONOMICCOOPERATIONANDDEVELOPMENT, 2010) e o Indicador de Alfabetismo Funcional (INAF) (INSTITUTO PAULO MONTENEGRO, 2009).

As causas relatadas são as mais variadas: falta de investimentos, falta de eficácia nos investimentos, profissionais mal preparados e mal remunerados, falta de gestão escolar, ausência de coordenação nos diversos níveis, falta de um organismo que integre a educação infantil, fundamental, média e superior, influência política na nomeação de diretores de escolas, má preparação dos diretores e outros sintomas de um sistema que não está produzindo os resultados esperados pela sociedade (ORGANISATION FOR ECONOMICCO-OPERATIONANDDEVELOPMENT, 2010).

No entanto, todas as causas citadas convergem para um problema comum: falta gestão! Um bom sistema de gestão antecede os fatores pontuais que devem ser tratados e os identifica, propondo melhorias e soluções de gargalos que impedem uma boa prestação de serviços nas áreas de educação, tecnologia e inovação.

A gestão pode ser feita por uma metodologia de quatro macroetapas: planejar,executar, controlar e estabelecer ações que possam corrigir os rumos e encaminhar para um novo ciclo. Este é o processo conhecido como metodologia PDCA (CAMPOS, 2009).

Figura 1: O ciclo PDCA

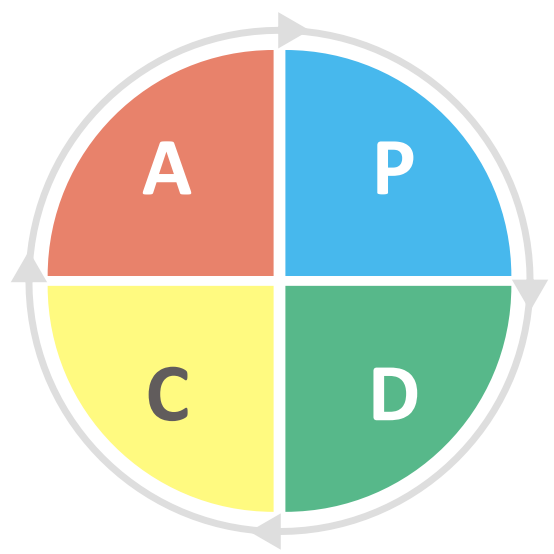

Fonte: NED SENAI SC (2012) 
Ao planejar, estabelecer objetivos e metas, construir métricas, acompanhar indicadores, analisar resultados e propor planos de ações preventivas ou corretivas, estão sendo identificadas as necessidades de interferência e oportunidades de melhoria na educação.

O objetivo deste artigo é analisar os benefícios da implementação de um sistema de gestão da qualidade na educação com base no ciclo PDCA.

Este artigo foi desenvolvido através de pesquisa bibliográfica e análise das informações coletadas.

\section{QUALIDADE NA EDUCAÇÃO}

A palavra qualidade vem do latim qualitas, e significa um atributo ou característica (MORWOOD, 1995). A palavra tem sido aplicada em diferentes situações, na indústria ou na prestação de serviços, cada uma com definições particulares, podendo significar: "fazer certo da primeira vez", "ausência de defeitos", "atender a expectativa do cliente", e várias outras definições. O conceito pode ser diferente dependendo do ponto de vista sob o qual é analisado, podendo ser o dequem oferece ou de quem recebe um produto ou serviço. Entender o conceito de qualidade é fundamental quando se pretende fazer sua gestão.

Da mesma forma, quando se trata da qualidade na educação, o termo também apresenta diferentes definições.

O Fundo das Nações Unidas para a Infância (UNITED NATIONS CHILDREN'S FUND, 2000) considera que a qualidade na educação está baseada em cinco pontos fundamentais, que são:

a) docentes saudáveis, bem nutridos e aptos a ensinar e aprender, apoiados por suas famílias e comunidades;

b) ambiente de ensino saudável, protetor, com fontes de informação e instalações que contemplem a igualdade de ensino e de acesso para os gêneros;

c) conteúdo adequado para o currículo e para a aquisição de competências básicas, especialmente em leitura, matemática e competências para a vida, com conhecimentos que contemplem gênero, saúde, nutrição, prevenção do HIV/AIDS e paz;

d) processos de ensino voltados para a criança, em salas de aula, escolas e conteúdos que facilitem o aprendizado e reduzam as diferenças;

e) resultados que privilegiem o conhecimento, habilidades e atitudes relacionados às metas de educação e participação positiva na sociedade. 
Educadores e pedagogos consideram a qualidade na educação sob o foco da construção e apreensão do conhecimento. Estudantes de cursos profissionalizantes buscam qualidade na educação com foco no preparo para o trabalho e na empregabilidade. Sob o ponto de vista da indústria, a qualidade na educação visa a competência profissional, habilidades e atitudes que levem a um aumento da produtividade. Para instituições privadas de ensino, aqualidade está intimamente relacionada com a competitividade que garanta sua sobrevivência no mercado. Para os órgãos governamentais de regulação da educação, a qualidade na educação abrange a formação docente, a pesquisa e extensão, os índices de aproveitamento de estudos, o regime de trabalho dos docentes, etc.

As diferentes definições exigem formas específicas de avaliar e medir a qualidade na educação, como o índice de candidatos por vaga, a rotatividade de docentes, a satisfação da força de trabalho com a instituição e com as condições de exercício da profissão, os índices de aproveitamento como PISA e INAF já citados, a taxa de empregabilidade dos egressos de uma instituição, o percentual de aprovação de estudantes de uma escola, e tantos outros, tão variados quanto os conceitos de qualidade na educação.

Mas, mesmo com tantas definições diferentes há um consenso de que qualidade na educação não é medida apenas pelo bom aproveitamento dos estudantes, mas é uma consequência de processos bem conduzidos que levam ao aprendizado, que oferecem ambiente adequado para a aquisição do conhecimento e de docentes bem preparados e bem instrumentalizados para a educação. Apenas para citar alguns fatores, nenhum dos aspectos acima, isolado, por melhor que seja, é capaz de garantir uma educação de qualidade para o estudante. É necessária uma conexão entre vários aspectos citados acima e que passam por infraestrutura, processos, pessoas e tantas outras abordagens dependendo de cada tipo de curso.

E a melhor maneira de se fazer esta conexão é através de um sistema estruturado de gestão com o objetivo de alcançar uma educação de qualidade, ou seja, é necessário que seja adotada uma gestão da qualidade na educação.

\section{GESTÃO DA QUALIDADE NA EDUCAÇÃO}

A adoção de um sistema de gestão de qualidade na educação busca assegurar que o planejamento, organização, controle e liderança sejam conduzidos assegurando assertividade e melhoria contínua do seu desempenho e, especialmente a qualidade da educação, ou seja: o desenvolvimento das competências do estudante.

Porém para que se obtenha êxito na estratégia de implementação do sistema de gestão de qualidade no âmbito da educação, alguns componentes devem ser considerados, de acordo com Xavier (1994): 
a) qualidade no ensino não é apenas o que se entende por qualidade de aula. É necessário colocar esta questão no contexto do projeto pedagógico da organização e, subordinado a ele, o projeto de cada curso;

b) a qualidade no ensino é o resultado de diversos processos de negócios: desde o momento e as razões que levaram a organização a criar um curso, até o perfeito atendimento das expectativas e necessidades do mercado em que atua, há muitos processos de negócios envolvidos, que levam à "boa" e/ou à "má qualidade", com seus respectivos custos, geralmente muito elevados;

c) a qualidade no ensino é fruto da parceria entre os clientes docentes/funcionários e a organização: é preciso ouvir com muita atenção os clientes para conhecer suas necessidades e expectativas e especificar clara e objetivamente o que se espera de nossos docentes/funcionários, a fim de que a organização possa atender suficientemente seus clientes;

d) a qualidade no ensino requer uma atitude proativa: fazer as coisas certas na primeira vez, eliminando todas as formas de desperdícios, requer planejamento, treinamento, desenvolvimento e responsabilidade;

e) a qualidade no ensino requer foco na análise e gestão das atividades de pesquisa, ensino e serviços de extensão à comunidade: a produção de conhecimentos, metodologias didáticas no "momento da verdade", bem como, os serviços de extensão à comunidade devem se adequar à estratégia de sobrevivência com competitividade das organizações;

f) a qualidade no ensino requer o envolvimento/compromisso de todos os docentes/funcionários e da própria organização com o processo de contínuo aperfeiçoamento.

Ainda segundo Xavier (1996), alguns fatores devem ser considerados quando é abordada a gestão da educação com foco na qualidade. Os principais são:

a) a gestão da qualidade na educação é um conjunto de princípios e métodos para a integração e cooperação de todos os membros da organização, com o objetivo de promover melhoria da qualidade na educação, aumentar a satisfação dos clientes e dos colaboradores;

b) é necessário o estabelecimento e manutenção de um padrão de atendimento que se adeque às necessidades dos clientes;

c) a gestão da qualidade na educação deve buscar uma melhoria contínua deste padrão de atendimento. 
As mudanças atuais que afetam nossa sociedade, assim como o advento de novas tecnologias, entre elas as de aplicação educacional, são alguns dos fatores que obrigam as empresas a analisarem seus processos e fazer com que sejam mais eficientes e eficazes. Os resultados financeiros adquirem importância cada vez maior, pois permitem a manutenção das atividades da organização, significam maior possibilidade de investimento no capital intelectual e na infraestrutura física e tecnológica. Especialmente no caso da última, que exige atualizações cada vez mais frequentes.

Para implementar ações que melhorem a eficiência e a eficácia dos processos educacionais é necessário que o gestor conheça e dimensione cada etapa do processo, com suas entradas e saídas. E mais ainda, é preciso conhecer as inter-relações entre estas etapas, com o conhecimento do impacto ou influência que uma etapa exerce sobre a outra.

Como se trata de uma mudança profunda, a implantação desse modelo enfrenta várias barreiras, pois mexe com o status quo, com o imobilismo, com o conformismo e com os privilégios. Portanto, a gestão da qualidade não deve ser vista como mais um programa de modernização. Trata-se de uma nova maneira de ver as relações entre as pessoas, na qual o benefício comum é superior ao de uma das partes (XAVIER, 1994).

Para que a gestão da qualidade total possa ocorrer em um sistema educacional, e superar as possíveis barreiras na sua implantação, Xavier (1995) aponta algumas características essenciais que devem ser consideradas:

a) o comprometimento político dos dirigentes;

b) a busca por alianças e parcerias (públicas e privadas);

c) a valorização dos profissionais da educação;

d) a gestão democrática;

e) o fortalecimento e a modernização da gestão escolar; e

f) a racionalização e a produtividade do sistema educacional.

Segundo Longo (1996) para que a efetiva implementação desse modelo gerencial ocorra, seja em processos de educação ou dos serviços técnicos e tecnológicos, torna-se imprescindível a realização de treinamento das partes envolvidas. Não existe qualidade total ou gestão da qualidade sem este componente vital, porque permite a aquisição de habilidades específicas necessárias ao novo paradigma gerencial.

Várias são as ferramentas que trabalham em prol de um sistema de gestão da qualidade efetivo (GUTIERRES, 2009), podendo envolver desde a adoção da gestão para a qualidade na educação e/ou a possibilidade de se implementar e manter o sistema de gestão da qualidade em organizações educacionais com base na NBR 15419:2006 - Sistemas de 
Gestão da Qualidade - Diretrizes para aplicação da NBR ISO 9001:2000 nas Organizações Educacionais.

O propósito desta diretriz é facilitar a compreensão dos requisitos estabelecidos na NBR ISO 9001:2000, a fim de implementar e manter o sistema de gestão da qualidade em organizações educacionais, de todos os tipos e portes.

A adesão às práticas de gestão da qualidade nas empresas, especialmente as fabris tem levado a muitas instituições educacionais a se questionar "Gestão da Qualidade na Educação?" Porém, ao transferir os métodos de gestão da qualidade desenvolvidos a partir de modelos de gestão fabris à escola, algumas diferenças importantes devem ser compreendidas (TRIBUS, 1992), conforme demonstrado no quadro 1.

Quadro 1: Aspectos que diferenciam a escola da indústria, sob o ponto de vista da gestão da qualidade:

\begin{tabular}{|} 
A escola não é uma fábrica. \\
Os alunos não são o produto. \\
Sua educação é o produto. \\
Os clientes para o produto são vários: os próprios alunos, \\
os pais, os futuros empregadores, a sociedade em geral. \\
Os alunos precisam ser “coadministradores" da sua \\
própria educação; e
\end{tabular}

Fonte: Tribus (1992)

Para Stukalina (2010), o papel da gestão da qualidade na educação tem se tornado mais representativo, pois a gestão pela qualidade tem sido percebida como um dos principais problemas para as organizações educacionais, sendo uma das principais tarefas para os gestores ao buscar dotar os participantes do processo de ensino-aprendizagem de um ambiente educacional eficaz e motivador.

Neste contexto, Stukalina (2010), considera a motivação dos alunos como um fator essencial para a melhoria da qualidade do ambiente pedagógico e para isso considera alguns procedimentos de gestão da qualidade que os gestores podem utilizar e proporcionar mudanças qualitativas no ambiente educacional. A avaliação é um deles e inclui a obtenção de feedback dos alunos, que é uma fonte valiosa de contribuições para análise no processo de melhoria da qualidade do ambiente educacional. 


\section{IMPACTOS DA GESTÃO DA QUALIDADE NA EDUCAÇÃO: ESTUDO DE CASOS}

A gestão da qualidade na educação impacta na sustentabilidade da instituição de ensino, seja no que se refere à competitividade (representada pelo número de alunos que escolhem a instituição), seja pelo atendimento às demandas da sociedade e da indústria, seja pela formação de profissionais e cidadãos sintonizados com o presente e atentos ao futuro e, finalmente, pelo desempenho financeiro.

A implementação de um programa de gestão da qualidade na educação inicia com a adoção de metodologias de gestão que contemplem planejamento, execução, controle e ajustes, ou simplesmente PDCA.

Esta metodologia foi desenvolvida na década de1950 pelo estatístico norte-americano William Edward Demings, mas sua divulgação se deu após a Segunda Guerra Mundial quando os japoneses implantaram e disseminaram a preocupação com o controle de qualidade em suas empresas. Demings esteve no Japão e disseminou o uso de técnicas estatísticas para o controle de qualidade, mas a maturidade da gestão da qualidade na indústria somente se deu com a vinda para o Japão, do engenheiro norte-americano J. M. Juran que conseguiu demonstrar que o controle de qualidade é uma ferramenta administrativa, que precisa da participação de todos os setores da empresa e que não deve basear-se apenas em análises estatísticas isoladas (WERKEMA, 2006).

Existem exemplos que comprovam que uma gestão adequada da qualidade na educação resulta em diferenciais na formação do aluno e do docente. Um destes é o caso da Brockton High School, em Massachussets, EUA, onde dada a situação de baixos índices de aprendizado aliado à alta evasão, levaram a um movimento de recuperação de alunos, considerando competências básicas de leitura, escrita, matemáticas e raciocínio lógico. A ação do gestor foi fundamental em transformar primeiro os professores e depois os estudantes. A recuperação dos índices de aprendizagem e das condições de ensino motivaram todos a reverter a situação daquela escola. A escola trabalhou, além das competências básicas de leitura, escrita, lógica e matemática, a autoestima dos alunos, preparando-os para as tomadas de decisões impostas pela vida e tornando-os pessoas melhores para a sociedade(VAZINS, 2009).

Em pesquisa baseada em um estudo de BrazosportDSI, (GOLDBERG; COLE, 2002) em um distrito escolar exemplar no Texas, que usou uma abordagem de gestão da qualidade, foram identificados resultados relativos a maior equidade e melhor desempenho do estudante, por meio do alinhamento do sistema e a melhoria dos processos pedagógicos.

Hofman, Dijkstra e Hofman(2008) apresentam os resultados de uma pesquisa sobre gestão da qualidade na Holanda onde as escolas foram classificadas em quatro tipos de gestão da qualidade: (a) um primeiro tipo em que quase não há gestão; (b) um segundo tipo de qualidade média da gestão; (c) um terceiro tipo caracterizado pela gestão da qualidade avançada, com um bom nível de responsabilização e melhoria da escola; e (d) um quarto tipo que é caracterizado como escolas de qualidade variável de gestão. 
Destaca-se que o tipo avançado de gestão da qualidade, em função das escolas serem mais ativas em termos de determinação e de melhoria na sua qualidade, apresentou uma maior qualidade de ensino-aprendizagem do que os outros três tipos de gestão da qualidade.

Adicionalmente, Hofman, Dijkstra e Hofman(2008) concluem que existem apenas pequenas discrepâncias entre os padrões de qualidade propostos pelas próprias escolas (interno) e das instâncias regulamentadoras da educação (externo). Além disso, os quatro tipos de gestão da qualidade acima se utilizam de indicadores de qualidade para avaliar a gestão das escolas. No entanto, o tipo mais avançado de gestão da qualidade está apoiado na gestão destes indicadores mais fortemente que os outros tipos.

Para Buse (2010) no processo educativo a qualidade não é produzida exclusivamente pela escola, como prestadora de serviços educacionais, mas pelos seus beneficiários e os clientes da educação.

Em estudo realizado por Grant, Mergen e Widrick (2004)é comparada a implementação de programas de gestão da qualidade no ensino superior nos Estados Unidos e em instituições acadêmicas internacionais. A pesquisa sugere vários exemplos de dados externos como auxílio em futuras implementações de qualidade de desempenho na educação, pois a coleta de dados de desempenho é fundamental para a gestão da qualidade, já que é um parâmetro do sucesso da educação desenvolvida pela escola em relação à concorrência. Além disso, informações obtidas de clientes são usadas para identificar problemas de concepção e conformidade nos processos educacionais e, em sua ausência a melhoria contínua é inexistente.

Iniciativas de gestão da qualidade na educação que conduzem a uma melhoria do sistema de educação em uma organização são louváveis e, como reconhecimento pelo empenho e implementação da gestão da qualidade na educação, a Fundação MalcomBaldrige ${ }^{1}$ criou o Prêmio MalcomBaldrige de excelência na educação que premia as melhores instituições de ensino com base nos seguintes critérios:
a) liderança;
b) planejamento estratégico;
c) foco no cliente;
d) monitoramento, análise e gestão do conhecimento;
e) foco na força de trabalho;
f) foco no processo;
g) resultados.

${ }^{1}$ BaldrigePerformanceExcellenceProgram, 2011. 


\section{GESTÃO DA QUALIDADE NA EDUCAÇÃO E O MÉTODO PDCA}

Para Lück (2000), a gestão escolar constitui um caráter de atuação que objetiva promover a organização, a coordenação, a mobilização e a articulação de todas as condições humanas e materiais na escola, com o intuito de garantir o avanço dos processos sócio educacionais da instituição de ensino, orientadas para o desenvolvimento de cidadãos capazes de enfrentar adequadamente a sociedade globalizada. Entende-se, dessa forma, que o objetivo final da gestão escolar é a aprendizagem efetiva e significativa dos alunos e é sobre este objetivo que se deve assegurar qualidade.

A conceituação de qualidade da educação, ou do ensino, precisa ser mais esclarecida na sua dimensão gerencial. Não faz sentido negar as dimensões formais e política da educação, ou seja, qualidade formal - competência para produzir e aplicar métodos, técnicas e instrumentos - e qualidade política, aquela que se refere à competência para projetar estratégias de formação e emancipação das novas gerações, de sujeitos sociais capazes de definir por si próprios o seu destino histórico. Restringir a conceituação de qualidade do ensino ao seu aspecto político-pedagógico constitui um grave equívoco (LONGO, 1996).

A busca da qualidade na educação deve estimular um olhar no qual a instituição de ensino é um sistema empresarial e, como tal, buscar a eficiência administrativa, pois quem se dedicar à análise do funcionamento dos sistemas de ensino acabará por encontrar provas evidentes de que a gestão é uma componente decisiva da eficácia escolar, tão rara de se encontrar no sistema educacional brasileiro, principalmente no ensino fundamental. Em virtude dessa situação, torna-se necessário adotar uma postura gerencial moderna e eficaz, para que os ventos da mudança criativa e inovadora soprem também para a educação (LONGO, 1996).

Essa postura está pautada na adoção de um método gerencial que é único, mas que existem diversas denominações utilizadas por diversas empresas de consultorias que querem fazer crer que seu método é melhor, porém são apenas denominações comerciais e todas são boas, pois o método é único: o Ciclo PDCA (CAMPOS, 2009).

Gerenciar tornou-se fator decisivo nas empresas de diferentes produtos ou serviços. E no caso da educação profissional, o controle sobre os índices de evasão escolar, aprovações e reprovações, satisfação do cliente, média de alunos por sala, resultado financeiro do produto e outros, são indicadores que podem auxiliar a empresa na sustentabilidade e no cumprimento de diretrizes organizacionais. Gerenciar torna-se o meio diferencial de competição entre as empresas.

Mas o que vem a ser o PDCA e suas implicações no meio gerencial? Administrar significa "Planejar", corresponde à etapa "P" do PDCA. Este método é aplicado para alcançar resultados dentro de um sistema de gestão e pode ser utilizado em qualquer empresa de forma a garantir o sucesso nos negócios, independentemente da área de atuação da empresa. O ciclo PDCA começa pelo planejamento, em seguida as ações planejadas 
são executadas; checa-se o que foi feito verificando se está em acordo com o planejado, de forma cíclica, e toma-se uma ação para eliminar ou ao menos minimizar defeitos do processo ou produto.

Os passos são os seguintes:

a) plan (planejamento): estabelecer uma meta ou identificar o problema (um problema é um resultado não esperado, ou seja, uma meta não alcançada); analisar o fenômeno (analisar os dados relacionados ao problema); analisar o processo (descobrir as causas essenciais dos problemas) e elaborar um plano de ação;

b) do (execução): realizar, executar as atividades conforme o planejado,capacitar as pessoas envolvidas e coletar dados para serem analisados;

c) check (verificação): monitorar e avaliar periodicamente os resultados, avaliar processos e resultados, confrontando-os com o planejado, objetivos, especificações e estado desejado, consolidando as informações, e se necessário, elaborar relatórios;

d) act (ação): Agir de acordo com a verificação, tendo como base as evidências coletadas, eventualmente determinar e confeccionar novos planos de ação, de forma a melhorar a qualidade, eficiência e eficácia, aprimorando a execução e corrigindo eventuais falhas.

Para Gutierres (2009) o ciclo PDCA é um instrumento básico e absolutamente geral para a obtenção da melhoria de processos e que pode tranquilamente ser aplicado nos processos educacionais. Um planejamento pedagógico é feito, discutido e analisado, e as responsabilidades são atribuídas para, em seguida, serem executadas na prática.

O controle, por meio de indicadores referentes ao sistema pedagógico, permite a avaliação de sua eficácia, pois com base em seus resultados são efetuadas ações corretivas e preventivas, visando, em primeira instância, atender ao que foi planejado e, em seguida, replanejar, incorporando as melhorias aplicáveis (GUTIERRES, 2009)

No âmbito educacional, de acordo com Gomes (2009) alguns critérios de qualidade são fundamentais para a gestão educacional, sendo interpretados como itens prioritários. Alguns deles são apresentados a seguir:

a) projeto político-pedagógico que possibilite dotar a escola de um sistema pedagógico eficaz;

b) currículo verdadeiro que permita que o currículo seja definido assegurando atualidade, contextualização e flexibilidade; 
c) aprendizagem institucional contemplando a educação, treinamento e desenvolvimento do corpo docente e os demais;

d) disciplina envolvendo um processo de educação da vontade oferecido aos estudantes de forma que compreendam os objetivos educacionais e mantenham-se firmes em função desses objetivos;

e) organização do tempo e espaço na construção de um ambiente interativo e prazeroso por meio da ampliação do tempo de permanência dos alunos.

As diretrizes devem ser oriundas das reflexões estratégicas da instituição de ensino associadas às estratégias definidas em nível corporativo, de unidades de negócio e funcionais. Nesse contexto, as diretrizes são guias para a ação gerencial, pautadas usualmente em necessidades específicas dos clientes, aumento da competitividade e melhorias.

Para Gomes (2009), são três as funções de uma instituição de ensino associadas aos níveis hierárquicos de uma instituição educacional:

a) funções de nível estratégico que tratam das definições de diretrizes (financeira, marketing, recursos humanos, educacional, expansão, entre outras) e representada pela alta direção da instituição, normalmente diretoria, conselho, etc;

b) funções de nível tático que integram as decisões estratégicas com as práticas operacionais, comunicando e incentivando os profissionais do nível operacional a assumirem o compromisso de encaminhar a escola em um dado rumo definido. Atuam, ainda, planejando, desenvolvendo por meio de pessoas, avaliando o desempenho do trabalho do executor, reconhecendo, melhorando e corrigindo o núcleo. Esta função é representada, tradicionalmente, pela direção, coordenações de curso, etc;

c) funções de nível operacional que envolvem as operações de execução da sala de aula, tarefas de apoio e funções administrativas operacionais que contemplam as atividades e decisões da rotina da instituição de ensino. 0 professor é a figura principal desse nível, além das secretárias, atendentes, coordenadoras pedagógicas, etc.

Assim, Gomes (2009) afirma que a gestão engloba o planejar, desenvolver, controlar e agir na melhoria contínua. Todo processo requer critérios e instrumentos para checarem se os objetivos e metas estabelecidos estão tendo progresso ou não, estes critérios são apresentados para cada um dos níveis de avaliação por meio da utilização de instrumentos de avaliação como se observa nos quadros abaixo. 
O presente artigo analisou a gestão da qualidade relacionada à educação e propõe formas de gerir a qualidade da educação tomando por base o PDCA. Considerando as informações coletadas na revisão bibliográfica, é possível perceber que o conceito de gestão encontra formas concretas de operacionalização no contexto educacional. De fato, percebe-se uma combinação de processos de gestão voltados ao controle e à melhoria da qualidade da educação para obtenção de resultados que se refletem na melhoria dos processos de ensino-aprendizagem.

A gestão da qualidade da educação não deve limitar-se somente ao seu aspecto políticopedagógico, pois a necessidade de eficiência nos processos de gestão é, também, um fator crítico de sucesso para a obtenção de um melhor desempenho do aluno quanto ao desenvolvimento de suas competências. Torna-se necessário que, ambos os olhares, mesmo que distintos, sejam convergentes e voltados a um propósito único: a educação de qualidade.

Diversos requisitos da qualidade podem ser atribuídos a educação, entretanto de acordo com os referenciais propostos neste estudo, foi possível identificar que o comprometimento de dirigentes, a formação de alianças, a valorização de profissionais e uma gestão democrática, moderna e focada em resultados que melhorem a eficiência dos processos educacionais em um ambiente motivador são elementos essenciais e distintivos na busca pela qualidade da educação.

A gestão da qualidade de educação, foco deste estudo, deve ser considerada como um conjunto de princípios e métodos para a integração e cooperação de todos os atores da comunidade escolar (pais, alunos, professores, funcionários, empresas, vizinhos e outros membros da sociedade civil) que ocorre a partir de um modelo ou método que proporcione a manutenção dos padrões de desempenho e sustente a busca da melhoria contínua.

Assim, o PDCA, como método universalmente conhecido e reconhecido se apresenta como uma metodologia de gestão simples e de fácil operação que pode ser aplicada no contexto educacional objetivamente. O PDCA permite planejar, executar, avaliar e tomar ações de correção e de melhoria, ou mesmo aprender com a execução, desde que essas ações sejam realizadas sistematicamente e resultem em ações firmes e consistentes, formando as bases para o processo de melhoria contínua da qualidade da educação.

A principal limitação desta pesquisa está na pequena quantidade de resultados empíricos de pesquisa publicados, além dos estudos de casos levantados em publicações científicas já que a extensão e a diversidade de dados forneceriam maiores subsídios para análise ao ser possível contextualizar a gestão da qualidade da educação em contextos próximos ao segmento específico da educação profissional. 
Implicações práticas podem ser concebidas a partir deste estudo tanto para pedagogos como gestores, ao possibilitar reflexões sobre como a educação e seus processos de apoio podem ser geridos com vista a um objetivo comum que é assegurar a evolução do estudante frente a critérios pré-estabelecidos de maneira eficiente. A implicação teórica que se retira dos casos analisados, apesar de suas limitações, é de que estudos sobre a gestão da qualidade da educação que integrem conhecimentos distintos e muitas vezes percebidos como antagônicos como a pedagogia e administração possibilitariam um avanço em ambos os campos de pesquisa.Ainda mais, implicações sobre os esforços da gestão sobre o desempenho dos estudantes merecem maior atenção teórica, culminando em oportunidades para futuras pesquisas nesta área.

Assim, estudos mais amplos realizados no âmbito da gestão da qualidade da educação e, particularmente, no âmbito de diferentes segmentos educacionais, níveis e estruturas de governança, sejam públicas, privadas ou em combinações peculiares como paraestatais, poderiam gerar um corpo de proposições consistentes para o entendimento de como se gera educação de qualidade, contribuindo, portanto, para a solidificação de conhecimentos ainda fragmentados sobre o tema.

\title{
QUALITY MANAGEMENT IN EDUCATION
}

\begin{abstract}
The quality of education has different definitions, depending on the perspective under which it is analyzed. Quality management in education seeks to improve processes, regardless of the definition applied. The objective of this paper is to analyze the benefits of implementing a system of quality management in education based on the PDCA cycle. The article was written based on a literature review. The PDCA methodology has four steps: plan, execute, control and establish actions that can correct the course and lead to a new cycle. When planning, setting objectives and targets, build metrics, monitor indicators, analyze results and propose plans of preventive or corrective actions, needs of interference and opportunities for improvement in education are being identified. This study identified some cases where the application of the PDCA methodology in educational processes confirms the theoretical studies that emphasize the importance of implementing quality management in education.
\end{abstract}

Keywords: Education. Management. Quality. 


\section{REFERÊNCIAS}

ASSOCIAÇÃO BRASILEIRA DE NORMAS TÉCNICAS. ABNT NBR 15419 Sistemas de gestão da qualidade - diretrizes para aplicação da ABNT NBR ISO 9001:2000 nas organizações educacionais. Rio de Janeiro, 2006.

BUSE, Maria. Premises of the quality management in education.Annals of the University of Petrosani, Economics, v.10, n. 4, p. 27-40, 2010.

CAMPOS, V. F. O verdadeiro poder. Nova Lima: INDG Tecnologia e Serviços Ltda., 2009.

GOLDBERG, Jacqueline S.; COLE, Bryan R. Quality Management in Education: Building Excellence and Equity in Student Performance. Quality Management Journal,[S.I.], v.9, n.4, p.8-22, 2002.

GOMES, Débora Dias. MBA Educação: a gestão estratégica na escola que aprende. Rio de Janeiro:Qualitymark, 2009.

GRANT, Delvin; MERGEN, Erhan; WIDRICK, Stanley.A Comparative Analysis of Quality Management in US and International Universities. Total Quality Management, [S.I.], v.15, n.4, p.423-438, 2004.

GUTIERRES, N. Seis Sigma e Lean Manufacturing. Banas Qualidade, São Paulo,v.18,n.203, p. 30-37, abr. 2009.

HOFMAN, Roelande; DIJKSTRA, H. Nynke J.; HOFMAN, AdiaanW.H.Internal versus external quality management. International Journal of Leadership in Education, [S. I.], v.11, n.3, p. 281-300, 2008.

INSTITUTO PAULO MONTENEGRO. Ação Educativa. INAF BRASIL 2009:indicador de alfabetismo funcional: principais resultados. São Paulo, 2009. Disponível em: <http:// www4.ibope.com.br/ipm/relatorios/relatorio_inaf_2009.pdf>. Acesso em: 19 set. 2012.

LONGO, Rose Mary Juliano. Gestão da Qualidade: evolução histórica, conceitos básicos e aplicação na educação,n.397. Brasília: IPEA, (RI/ IPEA/DPS), 1996.

LÜCK, H. Gestão escolar e formação de gestores. EmAberto, Brasília, v. 17, n. 72, p. 7-10, fev./jun. 2000. Disponível em: <http://www.publicacões.inep.gov.br/arquivos/\{7F F1DC84-64A4-42B8-B810-F68CD7193\}_em aberto_72.pdf>. Acesso em: 06 fev. 2011.

MORWOOD, J. (Ed.). The Pocket Oxford Latin Dictionary. Oxford, 1995.

ORGANISATION FOR ECONOMIC CO-OPERATION AND DEVELOPMENT. PISA 2009 Results: whatstudentsknowand can do.studentperformance in reading, mathematicsand science.v.1. (Programme for internationalStudentAssessment).2010. Disponível em: <http://www.oecd.org/pisa/pisaproducts/48852548.pdf>. Acesso em: 19 set. 2012. 
SERVIÇO NACIONAL DE APRENDIZAGEM INDUSTRIAL. Departamento Regional de Santa Catarina. Núcleo de Educação. Intranet. Disponível em:< https://www.sc.senai.br/>. Acesso em: 19 set. 2012. [acesso restrito].

STUKALINA, Yulia. Using quality management procedures in education: manging the learner-center educational environment. Baltic Journal on Sustainability, [S.I.], v.1, n.16, p. 75-93, 2010.

TRIBUS, Myron. Quality management in education. [S.I.]: Eric Education Resources Information Center, 1992.Disponível em: <http://www.eric.ed.gov/ERICWebPortal/ search/detailmini.jsp?_nfpb=true\&_\&ERICExtSearch_SearchValue_0=ED371441\&ERICE xtSearch_SearchType_0=no\&accno=ED371441>. Acesso em: 06 fev. 2011.

UNITED NATIONS CHILDREN'S FUND. Defining Quality in Education. Document No. UNICEF/PD/ED/00/02. [S.I.]: Programme Division Education, 2000. 44 p.

VAZINS, J. Turnaround at Brockton High.Emphasis on literacy brings big MCAS improvement. Boston Globe, 12 out. 2009. Disponível em: <http://www.boston.com/ news/education/k_12/mcas/articles/2009/10/12/turnaround_at_brockton_high/>. Acesso em: 19 set. 2012.

WERKEMA, Maria Cristina Catarino. Ferramentas estatísticas básicas para o gerenciamento de processos. Belo Horizonte: Werkema, 2006. 302 p.

XAVIER, Antonio Carlos da R. Rompendo paradigmas: a implantação da gestão da qualidade total nas escolas municipais de Cuiabá. Brasília: IPEA, 1994. 3 p. (Relatório Interno / IPEA. CPS ; 16/94).

Uma agenda para a melhoria da gestão da qualidade na educação brasileira. Brasília: IPEA, 1995.5 p.(Relatório Interno / IPEA. DPS ; 04/95).

.A gestão da qualidade e a excelência dos serviços educacionais: custos e benefícios de sua implantação. Brasília: IPEA,1996.17 p. (Texto para discussão no 408). 


\section{SOBRE OS AUTORES}

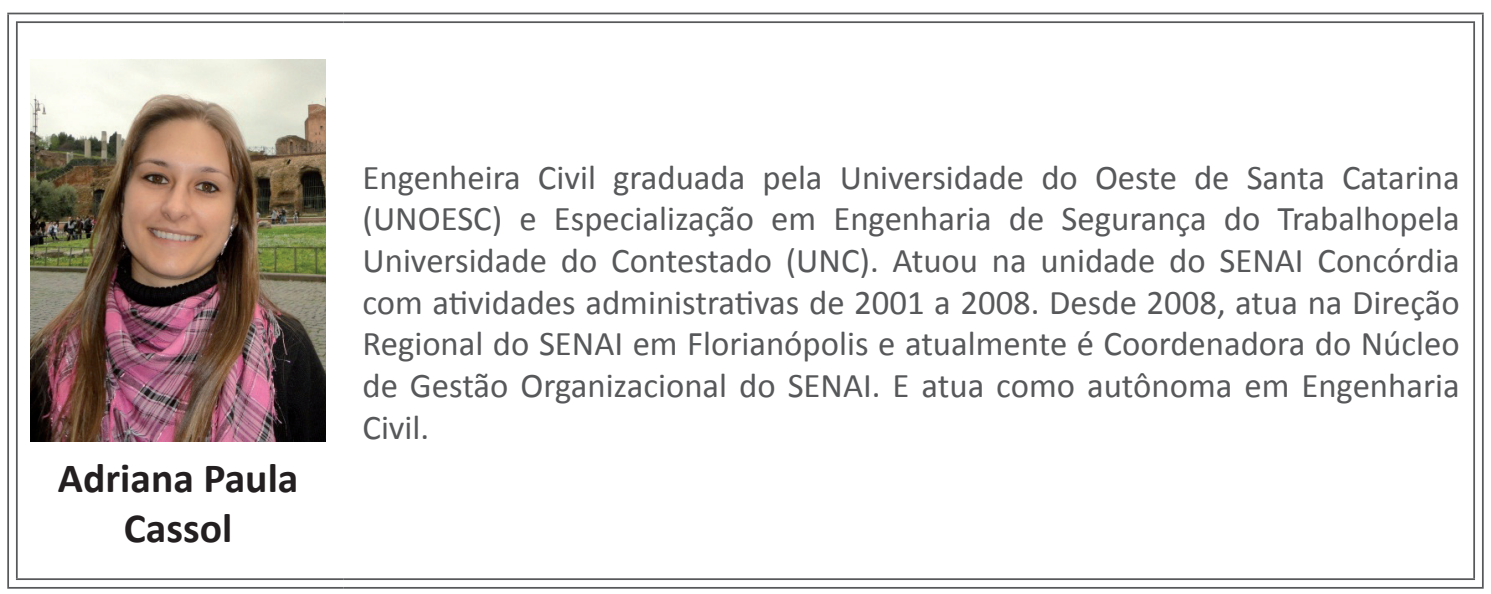

\begin{tabular}{|l|l||} 
Engenheiro Mecânico graduado Fundação Técnica Educacional Souza Marquez \\
(FTESM) e especialista em Tecnologia da Soldagem pela Universidade Federal \\
de Santa Catarina (UFSC). Atua como consultordo SENAI SC em Florianópolis \\
para implantação de Sistemas de Gestão da Qualidade com base na Norma NBR \\
ISO 9001, Modelo de Excelência da Gestão conforme Critérios de Excelência \\
da Fundação Nacional da Qualidade (FNQ) e Planejamento Estratégico. \\
Coordenador e docente do curso de Pós-Graduação MBA em Consultoria \\
Empresarial. Docente do curso de Pós Graduação em Gestão Estratégica de \\
Instituições de Ensino e Gestão de Serviços Compartilhados.
\end{tabular}

Mestre em Engenharia Elétrica, Especialista em Engenharia de Automação
Industrial e Graduado em Tecnologia Eletrônica e formação Pedagógica. Possui
experiência na Indústria de manufatura do segmento de automação industrial
e na área de educação profissional. Em educação profissional atua a mais de 17
anos, exercendo funções de Pesquisador na área de Engenharia Elétrica com
ênfase em Eletrônica Industrial; Professor da FATEC do SENAI SC em Jaraguá do
Sul e Gestor dos Núcleos de Eletroeletrônica, Informática e Metal Mecânica da
mesma unidade. Atualmente exerce a função de Diretor Adjunto do SENAI SC
em Jaraguá do Sul.




Formado em Engenharia Elétrica pela UFRGS (1966), mestrado em
ElectricalMachinesand Power Systems pela Universidade de Londres (1970).
Especialização em Engenharia de Segurança do Trabalho pela UDESC (1974).
Sua carreira profissional iniciou-se como Professor do Departamento de
Engenharia Elétrica em 1968, onde permaneceu até 1994, quando se
aposentou como Professor Titular.Assumiu o posto de Chefe de Departamento
de Engenharia Elétrica da UFSC nos períodos de 1992 a 1994 e 1971 a 1974.
De 1975 a 1980 foi Diretor do Centro Tecnológico da UFSC e Diretor Presidente
da Fundação para Ensino de Engenharia-FEESC.De 1990 a 1992, desenvolveu
atividades como Diretor de Desenvolvimento Científico e Tecnológico do
Governo do Estado.No período de 1994 a 1996 foi pesquisador do CNPq/
RHAE. Exerceu, também, função de Diretor na Iniciativa Privada e Engenheiro
na CELESC. Foi Diretor Superintendente do SENAI-CTAI no período de 1996 a
1998. Desde setembro de 1998 exerce o cargo de Diretor Regional do SENAI -
Serviço Nacional de Aprendizagem Industrial de Santa Catarina. É Conselheiro
do Conselho de Curadores da UFSC, do Conselho Estadual de Educação de SC
(CEE-SC) e do SEBRAE-SC.

Graduado em Administração de Empresas, mestre em Administração (2010)
e doutorando pela Universidade do Vale do Rio do Sinos - UNISINOS. Exerce
função de direção no Serviço Nacional de Aprendizagem Industrial na Unidade
SENAlsc em Criciúma. Tem experiência na área de Administração, com ênfase
na implantação de sistemas de gestão. Suas áreas de interesse são: estratégia,
educação (profissional), responsabilidade social e inovação social.


Médica Veterinária graduada pela Universidade Federal de Uberlândia (UFU), formada em Pedagogia pela Universidade do Sul de Santa Catarina (UNISUL), mestra em Ciência de Alimentos pela Universidad Autonoma de Barcelona (UAB), Espanha e doutoranda em Ciência de Alimentos pela Universidade

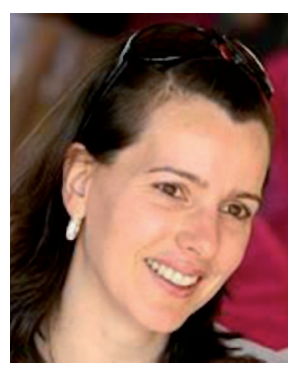

Simone Moraes

Raszl Federal de Santa Catarina (UFSC).

É Lead Assessor na ISO 9001. Atuou como instrutora e consultora do SENAI SC em Florianópolis para implantação de Sistemas de Gestão da Qualidade. Foi coordenadora e docente do curso de Pós-Graduação MBA em Gestão para Segurança de Alimentos a distância e trabalhou na implementação e em auditorias internas de Sistemas de Gestão de Qualidade e de Segurança de Alimentos em diversas indústrias da área. Autora dos livros HACCP: ferramenta essencial para a segurança de alimentos (OPAS, 2001); Sistema de Qualidade em Segurança de Alimentos: ABNT NBR ISO 22000:2006, Eurepgap e BRC (SENAI, 2007), Sistemas de Gestão de Segurança de Alimentos (SENAI, 2008). Foi consultora da Organização Pan-Americana da Saúde (OPAS/ OMS) entre 1999-2001.

Atua no Núcleo de Gestão Organizacional (SENAI/DR) com gestão de projetos e é coordenadora do Projeto Gestão da Qualidade nos Negócios do SENAIsc, desde outubro de 2010. 